Canadian

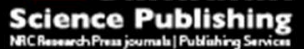

Canadian Journal of Civil Engineering Revue canadienne de génie civil

\title{
Out-Of-Plane Instability of Reinforced Masonry Uniaxial Specimens Under Reversed Cyclic Axial Loading
}

\begin{tabular}{|r|l|}
\hline Journal: & Canadian Journal of Civil Engineering \\
\hline Manuscript ID & cjce-2016-0006.R1 \\
\hline Manuscript Type: & Article \\
\hline Date Submitted by the Author: & $10-$-Dec-2016 \\
\hline Complete List of Authors: & $\begin{array}{l}\text { Azimikor, Nazli; Fast + Epp, } \\
\text { Brzev, Svetlana ; British Columbia Institute of Technology, Department of } \\
\text { Civil Engineering } \\
\text { Elwood, Kenneth ; University of Auckland, Civil and Environmental } \\
\text { Engineering } \\
\text { Anderson, Don; Professor Emeritus } \\
\text { McEwen, William; Canadian Masonry Contractor's Association }\end{array}$ \\
\hline Keyword: & $\begin{array}{l}\text { reinforced masonry, shear wall, out-of-plane instability, seismic resistance, } \\
\text { in-plane reversed cyclic loading }\end{array}$ \\
\hline
\end{tabular}




\section{Out-Of-Plane Instability of Reinforced Masonry Uniaxial Specimens Under Reversed Cyclic Axial Loading}

by

Nazli Azimikor ${ }^{1}$, Svetlana Brzev², Kenneth J. Elwood ${ }^{3}$, Donald L. Anderson ${ }^{4}$, and William McEwen ${ }^{5}$

1- M.A.Sc. Student, Department of Civil Engineering, University of British Columbia, 2329 W Mall, Vancouver, BC, V6T 1Z4, Canada

2- Faculty, Department of Civil Engineering, British Columbia Institute of Technology, 3700 Willingdon Ave, Burnaby, BC, V5G 3H2, Canada

3- Professor, Department of Civil and Environmental Engineering, University of Auckland, Auckland, New Zealand

4- Emeritus Professor, Department of Civil Engineering, University of British Columbia, $2329 \mathrm{~W}$ Mall, Vancouver, BC, V6T 1Z4, Canada

5- Executive Director, Canadian Masonry Contractor's Association, British Columbia Chapter 3636 East 4th Ave, Vancouver, BC, V5M 1M3, Canada

Corresponding Author:

Nazli Azimikor, P.Eng.

Fast + Epp

201 - 1672 West 1st Avenue,

Vancouver, BC V6J 1G1

Email: nazimikor@fastepp.com

Phone: (604)235-3125

Word Count: 8516 
Abstract:

Results of a study performed on the out-of-plane instability of reinforced masonry shear walls (RMSW) under seismic loading are presented. The study was conducted to gain understanding of the out-of-plane instability mechanism and the key factors influencing its development through testing of five reinforced masonry uniaxial specimens under reversed cyclic tension and compression. The specimens represented the end zone of a RMSW. The design parameters considered in the study included longitudinal reinforcement ratio and height-to-thickness ratio for the test specimens. It was found that onset of out-of-plane instability is strongly influenced by the level of tensile strains developed in the specimens and the reinforcement ratio and bar size. In this case out-of-plane instability occurred when out-of-plane displacements exceeded the critical value equal half the wall thickness. A study on full-scale RMSW specimens subjected to reversed cyclic loading, also undertaken under this research program, is expected to verify the findings of this study and contribute towards development of design criteria for out-of-plane stability of RMSW.

Key Words: reinforced masonry; shear wall; seismic resistance; out-of-plane instability; in-plane reversed cyclic loading 


\section{INTRODUCTION}

Reinforced masonry shear walls (RMSW) constructed using hollow concrete blocks reinforced with vertical and horizontal steel bars are commonly used as a Seismic Force Resisting System (SFRS) in Canada and internationally.

However, design applications of low-rise RMSW construction in Canada have been restricted by seismic design provisions of the Canadian masonry design standard CSA S304.1-04, which was in place at the time when the current research program was initiated (2010). Limits placed on the heightto-thickness ( $h / t$ ) ratio of ductile masonry walls (from 14 to 20 ) appear to be more conservative than corresponding provisions in standards from other countries with similar masonry construction practices, including the United States and New Zealand. For example, using an $h / t$ ratio of 14 and the common $200 \mathrm{~mm}$ thick concrete blocks limits the wall height to $2.8 \mathrm{~m}$ in Moderately Ductile RMSW; this is impractical for some of the common masonry applications, such as fire halls or school buildings. It should be noted that these provisions have been somewhat relaxed in the current Canadian masonry design standard CSA S304-14. In general, the upper bound for $h / t$ has been relaxed to 20 for Moderately Ductile RMSW classes (with force modification factor $R_{d}$ of 2). These provisions are further relaxed to 30 for lightly loaded rectangular section walls with axial compressive stress less than $0.1 \mathrm{f}_{\mathrm{m}}$ (provided that the size of compression zone is within the specified limits). However, the stringent $h / t$ limit (12) remained in place for a new RMSW class Ductile Shear Walls $\left(R_{d}=3\right)$, which can be potentially relaxed to 16 for lightly loaded walls.

These $h / t$ restrictions are intended to prevent lateral (out-of-plane) instability of RMSW subjected to axial stresses due to gravity loads and overturning moments caused by lateral seismic loads, as shown in Figure 1.

A rational explanation for lateral instability of RMSW during seismic loading was originally presented by Paulay and Priestley (1993). A shear wall can experience lateral instability when the longitudinal reinforcement in its end zones is subjected to compression loads subsequent to cycles of 
tensile plastic strain. Horizontal cracks form along the height of the plastic hinge region in the wall end zone during tension load cycles, and may not fully close in the subsequent compression load cycle. Due to the presence of open cracks and the residual plastic strains in the vertical reinforcement in the wall end zone, the end zone of the wall becomes very flexible and susceptible to significant outof-plane displacements under low compressive loads. It is possible to determine critical out-of-plane displacement beyond which instability will occur for a specific design case. This displacement is equal to the minimum distance between the centroid of steel and face of masonry block. For example, the critical displacement is equal to $t / 2$ for a wall with thickness $t$ and one layer of longitudinal reinforcement (where a reinforcing bar is placed in the centre of a hollow core), which corresponds to RMSW applications.

A comprehensive literature review of experimental research studies on RMSW subjected to in-plane reversed cyclic loads with flexure-dominant response has considered 92 specimens tested in the period from 1982 to 2009 (Azimikor et al. 2011). Seven flexure-dominant mechanisms were considered, including ductile flexural response; flexure/diagonal shear; flexure/sliding shear; flexure/out-of-plane wall instability; flexure/lap splice slip; flexure/toe crushing, and flexure/buckling of flexural reinforcement. Out of 92 specimens, only 3 failed due to out-of-plane instability. Based on the available experimental evidence, key design parameters influencing out-of-plane instability include: $h / t$ ratio, height/length ratio, level of applied axial compressive stress, longitudinal reinforcement ratio, and the level of tensile plastic strain in the reinforcement in the wall end zones. For example, Shedid et al. (2008) reported out-of-plane instability in two rectangular wall specimens with high longitudinal reinforcement ratios (1.31 and 1.17\%), while otherwise similar specimens with lower reinforcement ratios $(0.24 \%)$ tested in the same study did not experience instability. Priestley and He (1992) reported out-of-plane instability in the web of a T-shaped RMSW specimen. Experimental evidence related to out-of-plane instability of ductile reinforced concrete shear walls is more significant, and a comprehensive review of past experimental studies was performed by Herrick (2014). Out-of-plane instability of RMSW has not been observed in past earthquakes, however significant damage due to out-of-plane instability of reinforced concrete shear walls was observed in a 
few buildings affected by the 2010 Maule, Chile earthquake (M 8.8) (Westenenk et al. 2012) and the 2011 Christchurch, New Zealand earthquake (M 6.3) (Elwood 2013).

Insufficient experimental evidence on the subject prompted the need for a comprehensive research program with the objective to characterize out-of-plane instability in RMSW and develop related design provisions for Canadian masonry design standard. This paper describes the status and initial findings of a two-phase, five-year experimental program. Phase 1 of the program, discussed here, was focused on simulating the behaviour of the wall end zones using uniaxial specimens shown shaded in Figure 1 . The purpose of the study was to understand the out-of-plane instability phenomenon and identify key factors influencing its development. Note that these specimens were not able to simulate the actual boundary conditions along the height of the wall end zone, and did not take into account the effect of the strain gradient along the wall length. Phase 2 of the experimental program, currently in progress, consists of testing several full-scale RMSW specimens under in-plane reversed cyclic loading (Robazza 2013; Robazza et al. 2015). The results indicated that $h / t$ limits alone are not sufficient for evaluating the susceptibility of RMSW to out-of-plane instability due to in-plane lateral loading. This paper summarises the Phase 1 experimental study and its results; further details can be found in Azimikor (2012).

\section{EXPERIMENTAL PROGRAM}

\section{Test Specimens}

In Phase 1 of the experimental program, five full-scale block masonry uniaxial specimens ( $\mathrm{C} 1$ to $\mathrm{C} 5$ ) representing the end zone of a RMSW were subjected to reversed-cyclic tension and compression. Table 1 presents the specimen matrix and summarizes the key design parameters. All specimens were fully grouted, and had the same cross-sectional dimensions (590 mm length x $140 \mathrm{~mm}$ thickness). The overall height was $3.8 \mathrm{~m}$; equivalent to 19 courses of masonry and an average $10 \mathrm{~mm}$ mortar bed joint thickness. The specimens were reinforced with either two or three vertical reinforcing bars of different 
sizes distributed as shown in Table 1. Longitudinal reinforcement ratios ranged from 0.24 to $1.07 \%$, since one of the study objectives was to investigate the influence of reinforcement ratio on the development of out-of-plane instability mechanism. Height/thickness $(h / t)$ ratio for all specimens was equal to 27, that is, significantly higher than the limit of 14 for Moderately Ductile Shear Walls set by CSA S304-04. Specimens C3 to C5 were strengthened with a Glass Fiber Reinforced Polymer (GFRP) overlay in their upper portion to restrict tensile cracking and yielding of reinforcement to the lower un-strengthened portion of the specimen. This was accomplished by applying vertical GFRP strips on the two exterior faces, plus two horizontal strips confining the top and bottom of the GFRPreinforced region. The un-strengthened height of the specimen over which tensile cracking takes place is referred to as plastic height $\left(h_{p}\right)$ and represents the length of a plastic hinge in a RMSW. It can be noted from Table 1 that $h_{p}$ is equal to the overall height $(3800 \mathrm{~mm})$ only for specimens $\mathrm{C} 1$ and $\mathrm{C} 2$. For specimens C3 to C5 where GFRP was applied, $h_{p}$ was taken as the maximum length of the specimen over which tensile cracking was observed.

There were two motivations for installing the GFRP wrap: 1) to reduce the height of the plastic hinge zone (the height over which tensile cracking occurred), and 2) to overcome an issue with the gapping crack at the interface with the steel plate that was observed during the initial testing of specimen $\mathrm{C} 3$.

In the application of the GFRP, one of the key points was to anchor the wraps properly at the top, so the wraps were extended on the top steel plate and secured with steel angles that were bolted to the top plate. This approach was effective in reducing the crack at the top. However, it did complicate the experimental observations since some tensile strain still penetrated into the GFRP wrapped portion of the specimen and the inflection point was shifted.

Despite these complications, the application of GFRP helped achieve the purposes of the experimental program which was to observe out of plane instability for varying plastic hinge heights. Moreover, comparing the accumulative size of the cracks formed within the portion of the specimen which was not wrapped by GFRP to the tensile displacement imposed on the walls, it was observed that the 
application of GFRP was successful in limiting tensile strain to the lower portion of the wall (which was not wrapped). Therefore, while this approach had its limitations with regards to the complex boundary conditions, it was considered an acceptable approximation of the localized behaviour of wall ends under cyclic tension and compression.

The test setup was custom designed for this study to ensure that uniaxial tension and compression stresses were applied to the specimen in a uniform manner. Longitudinal reinforcing bars in each specimen were welded to rigid steel plates at each end to enable tension to be applied to the specimens. The testing frame consisted two double-acting MTS actuators (capacity $889 \mathrm{kN}$ each) mounted vertically parallel to either face of the specimen, and anchored to the strong floor at the bottom and the top loading beam. Two pantographs were used to restrain lateral displacements and rotation of the top loading beam while allowing vertical movement. The instrumentation consisted of 16 displacement transducers (linear and string potentiometers) which measured axial and out-of-plane displacements of the specimen. Further details of the test setup and instrumentation are provided in Azimikor (2012).

\section{Material Properties}

Construction was performed using $150 \mathrm{~mm}$ thick hollow concrete blocks with two cells. Although 200 $\mathrm{mm}$ thick blocks are most common in masonry construction in Canada, blocks with $150 \mathrm{~mm}$ nominal thickness (140 mm actual) were used to achieve maximum $h / t$ ratio within the height constraints of the test setup. Masonry material testing was performed at 28 days after the construction following the procedures outlined in pertinent Canadian standards: CSA A165-04 for blocks, and CSA A179-04 for mortar and grout. Average compressive strength for the blocks based on testing 9 specimens was 43.0 MPa based on the net area. It should be noted that the reported strength is significantly higher than 15 MPa compressive strength used for masonry block construction in Canada. Type S mortar was used, and an average compressive strength based on testing of eighteen $50 \mathrm{~mm}$ cubes was $15.8 \mathrm{MPa}$, with the coefficient of variation (COV) of $17.5 \%$. Note that the strength exceeded the minimum required 
strength of 12.5 MPa set by CSA A179 standard. Coarse grout was used for construction, and the mix consisted of 1:3:2 proportion of Portland cement, sand, and aggregate by volume, with a $10 \mathrm{~mm}$ maximum aggregate size. The grout compressive strength was $17.2 \mathrm{MPa}(\mathrm{COV}=8.6 \%)$, based on testing 10 cylinders ( $100 \mathrm{~mm}$ in diameter by $200 \mathrm{~mm}$ long) cast in non-absorbent moulds; this exceeds the minimum 12.5 MPa value per CSA A179 standard. The average masonry compressive strength, $\mathrm{f}_{\mathrm{m}}$, was $20.3 \mathrm{MPa}$, based on 3 two-block-high grouted masonry prisms (COV=6.3\%). In addition, 5 two-block-high hollow prisms were tested, with average strength, $\mathrm{f}_{\mathrm{m}}$, of $23.0 \mathrm{MPa}$ based on the net area $(\mathrm{COV}=14.0 \%)$. Note that the compressive strength values were corrected to take into account the height-to-thickness ratio (based on CSA S304-14 provisions). Tensile strength tests were conducted on 15 reinforcing bar specimens, 5 from each bar size used for specimen construction: $10 \mathrm{M}, 15 \mathrm{M}$, and 20M. The average yield strength was $584 \mathrm{MPa}, 527 \mathrm{MPa}$, and $464 \mathrm{MPa}$ respectively (average COV for all specimens was $4.7 \%$ ). These values are significantly higher than the characteristic yield strength of $400 \mathrm{MPa}$ for Grade 400 steel. The average yield strain for all specimens was $0.26 \%$, and the strain corresponding to the onset of strain hardening was $1.5 \%$. The specimens were prepared and tested according to CSA-G30.18-M92 (R2002) standard.

\section{Testing Procedure}

Two different loading protocols were used in the experimental program: monotonic compression loading (specimen $\mathrm{C} 1$ ) and reversed cyclic tension and compression loading (specimens $\mathrm{C} 2$ to $\mathrm{C} 5$ ). The test data obtained from specimen $\mathrm{C} 1$ was used to obtain a realistic estimate for the masonry modulus of elasticity and the compression load capacity, $\mathrm{P}_{\mathrm{cr}}$. The loading protocol for specimen $\mathrm{C} 2$ is shown in Figure 3. Specimens C3 to C5 were loaded according to the same loading protocol as target. However, the number of cycles and the magnitude of tension and compression had to be slightly adjusted during the testing depending on the response of each specimen in order to prevent its premature failure. Displacement- and force-controlled loading protocols were used for tension and compression cycles respectively. The target tensile displacements were expressed in multiples of the yield displacement, $\Delta_{\mathrm{y}}$. Note that $\Delta_{\mathrm{y}}$ corresponds to the onset of yielding in longitudinal reinforcement 
estimated using the average yield strain obtained from the reinforcement testing. The compression load was limited to half the compression capacity, $\mathrm{P}_{\mathrm{cr}}$, for the specimen.

Given the focus of the study on the out-of-plane failure mode, it was critical that the loading protocol be chosen to maximize the likelihood of observing the failure mechanism of interest. The first specimen tested had a height-to-thickness ratio (27) significantly higher than the maximum allowed in the 2004 edition of CSA S304 code (14 to 20). Yet, when subjected to pure axial load, it did not experience any out of plane instability. Therefore, when developing the cyclic loading protocol for the subsequent specimens where an out-of-plane failure was desired, it was important to select a consistent yet low enough magnitude of the compressive force such that crushing failure would be prevented. The value of $1 / 2 \mathrm{P}_{\mathrm{cr}}$ was felt to be an appropriate magnitude to achieve the abovementioned purposes. The response of specimens $\mathrm{C} 3$ to $\mathrm{C} 5$ to the magnitude of compressive load was closely monitored during testing as to make sure masonry crushing did not precede lateral instability.

\section{FAILURE MECHANISMS}

The following failure mechanisms were observed during the testing: crushing, local reinforcement buckling, and global out-of-plane instability. The characteristics of each mechanism are explained in this section.

Crushing mechanism (see Figure 4a) was associated with the specimen reaching its axial compression load capacity. This mechanism was observed only in specimen $\mathrm{C} 1$ which was subjected to monotonic uniaxial compression loading. The failure was characterized by formation of major vertical splitting cracks along head joints in the top third portion of the specimen. The cracking was followed by face shell spalling of masonry blocks in the damaged region, and it culminated in the failure that was accompanied by a loud popping sound. The presence of longitudinal reinforcing bars did not affect the ultimate capacity of the specimen, although bond between the bars and the grout appeared to be satisfactory. The specimen failed at a compressive load of $1400 \mathrm{kN}$, corresponding to a compressive strength of $17 \mathrm{MPa}$ and a compressive strain of $0.12 \%$. Note that the compressive strength at failure 
was less than the average masonry compressive strength of $20.3 \mathrm{MPa}$ obtained from the testing on grouted prisms. This difference can be partially attributed to the fact that prism strength was obtained based on the specimens with stack bond, while the full-scale test specimens were built in running bond.

Local reinforcement buckling mechanism was observed in specimen C5 with the lowest longitudinal reinforcement ratio of $0.24 \%$ and the smallest longitudinal bar size (10M) (see Table 1). A significant vertical splitting crack was observed close to the specimen midheight (below the GFRP-reinforced portion) at a tensile load cycle corresponding to displacement of $4.3 \Delta_{\mathrm{y}}$. Out-of-plane displacements continued to increase in subsequent cycles, however the rebar at the location of vertical crack started to push outward and caused spalling of the face shell and crumbling of the grout at this location. The specimen continued to restore its vertical alignment and did not experience global instability, in spite of maximum out-of-plane displacements on the order of $0.43 t$ (close to the critical value of $0.5 t$ beyond which instability is expected to take place). The maximum tensile displacement of $5.9 \Delta_{\mathrm{y}}$ (corresponding to tensile strain of $1.6 \%$ ) was attained during the testing. The failure was characterized by localized buckling of exposed $10 \mathrm{M}$ bars, and masonry compression failure due to reduced crosssectional area after the face shell spalling and crumbling of grout in the previous cycles (see Figure 4b). A possible explanation for this mechanism is that, due to a smaller amount of reinforcement, a smaller compressive load on the edge of the closing crack is required to restore balance across the specimen thickness (compared to other specimens). In this case, significant tensile strains are required to allow the specimen to move laterally outward beyond the point of return before the onset of crack closure. In addition, larger tensile strains combined with reinforcing bars with smaller area and moment of inertia resulted in bond degradation between the grout and the rebar which in turn resulted in local buckling of the reinforcement. This was confirmed by comparing the buckling load of $2-10 \mathrm{M}$ bars with the load at which the specimen began to experience out-of-plane displacement. If the laterally unsupported length of the bars had been reduced to $400 \mathrm{~mm}$ (equivalent to two courses of masonry), their combined buckling load would be equal to $9.1 \mathrm{kN}$; this is comparable to the $8 \mathrm{kN}$ load 
attained during the final loading cycle before the failure. This mechanism was previously observed in slender RC shear walls subjected to reversed cyclic loading (Valenas, Bertero, and Popov 1979).

Global out-of-plane instability was observed in specimens C2, C3, and C4. The mechanism developed when the specimens were subjected to compressive loads as low as $118 \mathrm{kN}$, followed by a load cycle where large axial tensile deformations were applied (corresponding to tensile strains ranging from 0.8 to $1.7 \%$ ). Note that the compression load was on the order of $8 \%$ of the compression capacity based on specimen $\mathrm{C} 1$ testing. The instability was characterized by significant out-of-plane displacements in excess of the critical displacement $(0.5 t)$, as illustrated in Figure $4 \mathrm{c})$. The tests showed that smaller applied axial tensile strain is needed to cause out-of-plane instability in specimens with higher $\mathrm{h}_{\mathrm{p}} / \mathrm{t}$ and longitudinal reinforcement ratios. Global out-of-plane instability mechanism will be discussed in detail in the next section.

\section{CHARACTERIZATION OF OUT-OF-PLANE INSTABILITY}

\section{The Mechanism}

The response of specimens $\mathrm{C} 2$ to $\mathrm{C} 5$ under reversed cyclic loading was similar. In the tension halfcycle, horizontal cracks developed along most bed joints in specimen $\mathrm{C} 2$. However, in specimens $\mathrm{C} 3$ to C5 horizontal cracks were limited to the region without GFRP strips, that is, lower portion of the specimens. With increasing applied tensile strains, the cracks widened and their distribution became more uniform. Once the reinforcement had experienced tensile strains beyond yield, most cracks remained open after unloading from the tension half-cycle. At that stage, small out-of-plane displacements were observed in the specimens. While the cracks were small, they closed gradually under increasing compressive loading, and the specimens restored their original vertical alignment. All cracks eventually closed and the specimens were subjected to pure axial compression across the entire cross-section at the peak of the compression half-cycle. 
With increasing peak tensile strain levels in successive loading cycles (see loading protocol in Figure 3), the specimens experienced increasing out-of-plane displacements during the compression halfcycle prior to full crack closure. The instability was characterized by continuous lateral movement of the specimen under increasing compressive loads. Eventually, local crushing of the face shells was observed at the compression edge of a crack. However, in specimen C5 longitudinal bars de-bonded from the grout and experienced local buckling prior to reaching global instability of the entire specimen, as discussed in the previous section.

Development of the out-of-plane instability mechanism in specimens $\mathrm{C} 2$ to $\mathrm{C} 4$ can be explained on a generic loading cycle diagram shown in Figure 5, which was developed based on the response of test specimens as characterized by plots presented in Figures 7 and 8 and finding common patterns of behaviour, including the point at which instability took place.

The cycle consists of a loading path $\boldsymbol{o - a} \boldsymbol{a}^{\prime}$, during which the specimen was subjected to large tensile strains, followed by an unloading path $\boldsymbol{a}^{\prime}-\boldsymbol{b}$, and subsequent reloading of the specimen in compression. There are two alternative scenarios for the compressive loading path: i) path $\boldsymbol{b}-\boldsymbol{c}-\boldsymbol{d}-\boldsymbol{g}-\boldsymbol{h}$, when the specimen restored vertical alignment and the testing continued, or ii) the specimen experienced failure due to global instability; this could occur either through path $\boldsymbol{b}-\boldsymbol{c}-\boldsymbol{f}$ (global out-of-plane instability characterized with large displacements) or $\boldsymbol{b}-\boldsymbol{c}-\boldsymbol{d}-\boldsymbol{e}$ (global instability combined with the localized masonry crushing).

The specimen was initially loaded in tension through path $\boldsymbol{o}-\boldsymbol{a}^{\prime}$ (see Figure 5). At point $\boldsymbol{a}^{\prime}$, the specimen will have already experienced plastic tensile strains due to yielding of longitudinal bars. As a result, large uniformly distributed horizontal cracks developed along the masonry bed joints, as shown in Figure 6a. During the unloading path $\boldsymbol{a}^{\prime}-\boldsymbol{b}$, the reinforcing bars recovered elastic strain and the crack widths reduced but remained open due to residual plastic strain. The masonry contraction during this phase was negligible.

Subsequently, the specimen was reloaded in compression (path $\boldsymbol{b}-\boldsymbol{c}$ in Figure 5), and the crack size 
was further reduced. During this phase, the reinforcing bars had to resist the entire applied compression load. As a result, the lateral stiffness of the specimen was reduced and the entire specimen would experience out-of-plane displacements due to even minor reinforcing bar eccentricities. These out-of-plane displacements caused the rotation of horizontal cracks (point $c$ ), as shown in Figure $6 b$.

As the compression loading continued along path $\boldsymbol{c}-\boldsymbol{h}$, lateral deflections would increase until the cracks started to close on one side of the specimen, and the contact between the adjacent blocks was achieved (point $\boldsymbol{d}$ ). When the crack size and out-of-plane displacements were sufficiently small, internal compression forces would develop at the point of contact, thereby providing a restoring force. The specimen would continue to restore its vertical alignment under increasing compression load, and when yielding of reinforcement in compression took place (point $g$ ). At the end of the compression half-cycle (point $\boldsymbol{h}$ ), all cracks closed and the entire cross-section was subjected to compression. The specimen maintained stability and the testing would continue.

Global instability occurred when the peak out-of plane displacements reached the critical out-of-plane displacement of $0.5 t$, and the internal forces were no longer able to restore the P- $\delta$ demands caused by the out-of-plane wall movement. Global instability was accompanied by significant tensile strains; this is because as the specimen experienced large lateral displacements in the subsequent compression cycles, it reached the critical out-of-plane displacement before the contact across the cracks could be attained (point $f$ ). Global out-of-plane instability could also be accompanied by localized masonry crushing when the cracks closed on one side after the critical out-of-plane displacement was attained (point $\boldsymbol{e})$.

Figure 7 shows the axial force versus nominal axial displacement hysteresis curves for specimens $\mathrm{C} 2$ to $\mathrm{C} 5$. The nominal axial displacement denotes an average displacement along the height over which the tensile cracking may be possible. For specimen $\mathrm{C} 2$ this corresponds to the full height, however for specimens $\mathrm{C} 3$ to $\mathrm{C} 5$ this height should ideally correspond to a portion of the specimen that was not 
strengthened with a GFRP overlay. However, it was evident from the test results that some cracking took place along the height of the GFRP-reinforced portion of the specimen. The plastic length $\left(h_{p}\right)$ values shown in Table 1 were determined from the specimen elongation that resulted in tensile yielding, considering the average steel yield strain of $0.26 \%$. These axial displacements were used to derive tensile strains in the specimens that will be discussed in the next section.

Figure 8 shows the axial force versus out-of-plane displacement hysteresis curves for specimens $\mathrm{C} 2$ to C5. While the loading protocol for all specimens followed a general pattern, some judgement was exercised during each experiment to modify the protocol for achieving the most useful specimen behaviour. Therefore, specimens were subjected to different number of loading cycles; this can be observed from hysteresis curves on Figure 8. It can be also seen from these plots that some out-ofplane displacements were recorded even when the specimens were subjected to tension. This can be attributed to the eccentricity of a reinforcing bar centroid with regards to the centroid of the wall section. Recall that the steel plate placed on top of the specimen was directly welded to the reinforcing steel. Therefore, there was a pre-existing crack at the interface between the steel top plate and the specimen end. As the actuators moved upward and tensile force was applied to the reinforcement, it was expected that the specimen might experience minor out-of-plane displacements. However, the displacements were relatively small and did not continue to increase with increased applied tensile force.

In the compression cycle, the out-of-plane displacement continued to increase until all cracks closed. The magnitude of maximum out-of-plane displacements also increased with each subsequent compression cycle. As previously discussed, this was attributed to the increasing tensile strains experienced by the reinforcement which consequently produced progressively increasing tensile cracks. It can be seen from Figure 8 that global instability of specimens C2, C3, and C4 occurred when out-of-plane displacements exceeded the critical displacement of $0.5 t$.

\section{Tensile Strains}


Results of the experimental study have shown that tensile strain is the critical parameter for assessing the likelihood for out-of-plane instability of RMSW subjected to combined gravity and in-plane lateral seismic loads.

A generic axial force versus axial strain loading cycle shown in Figure 9 will be used to explain the key strain components. The maximum tensile strain, $\varepsilon_{\mathrm{sm}}$, can be expressed in the following form, which was originally proposed by Chai and Elayer (1999):

$\varepsilon_{s m}=\varepsilon_{e}+\varepsilon_{r}+\varepsilon_{p}^{*}$

\section{Eq. 1}

where $\varepsilon_{\mathrm{e}}$ is an elastic recovery strain, $\varepsilon_{\mathrm{r}}$ is a reloading strain, and $\varepsilon_{\mathrm{p}}{ }^{*}$ is a residual plastic strain. The above equation was developed for assessing stability of reinforced concrete columns, but the concept may be applicable to reinforced masonry uniaxial specimens.

Elastic recovery strain, $\varepsilon_{\mathrm{e}}$, corresponds to elastic recovery process related to unloading path $\boldsymbol{a}^{\boldsymbol{\prime}}-\boldsymbol{b}$ shown in Figure 9. For an elastic-perfectly plastic tensile response, $\varepsilon_{\mathrm{e}}$ should be equal to the yield strain, $\varepsilon_{\mathrm{y}}$. However, given that strain hardening may be expected at higher strain levels, $\varepsilon_{\mathrm{e}}$ may be larger than $\varepsilon_{\mathrm{y}}$. Reloading strain, $\varepsilon_{\mathrm{r}}$, is associated with out-of-plane displacement of longitudinal bars under small axial compressive loads, that is, up to the crack closure (point $\boldsymbol{d}$ ). The remaining portion of the total tensile strain is equal to the residual plastic strain, $\varepsilon^{*}$. This strain corresponds to the sum of the open gaps that exist along the horizontal cracks after the specimen has already attained the critical out-of-plane displacement $(0.5 t)$.

The strain values obtained during the experimental study are presented in Table 2. Note that there is an error associated with determining the components of the total strain from the test results. It was difficult to establish with certainty at what point the specimen started to move laterally and when did the crack closure begin. It is also evident that the approaches employed for estimating $\varepsilon_{r}$ and $\varepsilon^{*} p$ 
components are highly idealistic since not all cracks begin to close simultaneously. Moreover, $\varepsilon^{*} p$ was determined based on the maximum curvature at mid-height while the curvature along the remainder of the height is ignored.

It can be seen from the table that the critical tensile strains in various specimens ranged from 0.79 to $1.69 \%$. Out-of-plane instability occurred at a lower level of applied axial tensile strain in specimens characterized by higher $h / t$ value and reinforcement ratio $(\rho)$. For example, specimen $\mathrm{C} 2$ which experienced instability at the lowest tensile strain of $0.79 \%$ was characterized by the largest plastic hinge height $\left(h_{p}\right)$ of $3800 \mathrm{~mm}$, and the highest reinforcement ratio $(\rho=1.07 \%)$. A similar trend was observed for specimen $\mathrm{C} 3$, which experienced instability at the strain of $0.80 \%$ and was also characterized by relatively low $h_{p}$ and $\rho$ values (3462 $\mathrm{mm}$ and $0.71 \%$ respectively). The remaining specimens (C4 and C5) achieved significantly higher tensile strains at failure (1.69 and 1.46\% respectively), but they had still smaller $h_{p}$ and $\rho$ values. Note that the maximum lateral displacements in all specimens were in the range from 0.40 to $0.46 t$, that is, close to the theoretical critical value of $0.5 t$.

The tensile strains recorded in the experimental study were compared with tensile strain demands in ductile RMSW examples designed according to CSA S304-14 standard. A parametric study was performed to determine a range of ultimate tensile strains in typical $200 \mathrm{~mm}$ thick RMSW with the same length $(3 \mathrm{~m})$ and uniformly distributed longitudinal reinforcement. The key parameters were reinforcement ratio, $\rho$, and the masonry compressive strength, $\mathrm{f}_{\mathrm{m}}$. It was assumed that the walls were reinforced with longitudinal reinforcing bars (Grade 400 steel). Two levels of axial pre-compression were considered: 5 and $10 \%$ of the masonry compressive strength, that is, $0.05 \mathrm{f}_{\mathrm{m}}$ and $0.1 \mathrm{f}_{\mathrm{m}}^{\prime}$. The $\rho$ values ranging from 0.1 to $0.7 \%$ were considered; the lower bound corresponds to the minimum seismic reinforcement according to CSA S304 standard, and the upper bound reflects actual reinforcement in some of the test specimens (see Table 1). Two masonry compressive strength $\left(\mathrm{f}_{\mathrm{m}}\right)$ values were considered: 10 and $25 \mathrm{MPa}$; the lesser value represents typical masonry strength while the 
higher value reflects the experimental strength value. It was assumed that the maximum compressive strain $\left(\varepsilon_{\mathrm{mu}}\right)$ is equal to 0.0025 ; this value is used for the ductility check according to CSA S304 standard.

The results show that the highest tensile strain of $1.9 \%$ may be expected in lightly loaded and lightly reinforced walls, that is, when axial pre-compression is $0.05 \mathrm{f}_{\mathrm{m}}, \rho=0.1 \%$, and $\mathrm{f}_{\mathrm{m}}=25 \mathrm{MPa}$. The tensile strains are significantly influenced by the level of axial pre-compression: significantly higher tensile strains are expected at lower pre-compression level $\left(0.05 \mathrm{f}_{\mathrm{m}}^{\prime}\right)$ than at higher pre-compression $\left(0.1 \mathrm{f}_{\mathrm{m}}^{\prime}\right)$ for the same reinforcement ratio $\rho=0.1 \%$; the respective strain values are 1.9 and $1.0 \%$. Note that the tensile strain level is somewhat affected by the masonry compressive strength: a lower strain $(0.6 \%)$ was obtained when $\mathrm{f}_{\mathrm{m}}=10 \mathrm{MPa}$ compared to the strain of $0.8 \%$ for $\mathrm{f}_{\mathrm{m}}=25 \mathrm{MPa}$ (note that $\rho=0.3 \%$ and axial pre-compression was $0.1 \mathrm{f}_{\mathrm{m}}$ in both cases). It should be also noted that high tensile strains correspond to relatively large curvatures and small compression zone depths; this can be expressed through the $\mathrm{c} / 1_{\mathrm{w}}$ ratio, where $\mathrm{c}$ is the neutral axis depth and $1_{\mathrm{w}}$ is the wall length. The parametric study has shown that high tensile strains in excess of $0.8 \%$ correspond to $\mathrm{c} / \mathrm{l}_{\mathrm{w}}$ ratios in the range from 0.1 to 0.2 (the smallest $\mathrm{c} / \mathrm{l}_{\mathrm{w}}$ ratio of 0.11 corresponds to the largest strain of $1.9 \%$ ). It can be expected that the flexural failure mechanism in a RMSW with low $\mathrm{c} / \mathrm{l}_{\mathrm{w}}$ ratio is toe crushing, that is, the failure is governed by compression capacity of the masonry compression zone; therefore, out-of-plane instability mechanism cannot take place irrespective of high tensile strain levels. This observation was confirmed by recent tests on full-scale RMSW performed under the same experimental program (Robazza et al. 2015).

\section{CONCLUSIONS}

Based on the findings of this experimental study, it can be concluded that the magnitude of applied tensile strain is the primary factor that determines the potential for out-of-plane instability in the end zone of RMSW. A critical amount of tensile strain which caused opening of large horizontal cracks was required to allow the specimen to experience lateral displacements beyond the critical value of $0.5 t$ before the crack closure on one side of the specimen. This was confirmed by the tests on 
specimens $\mathrm{C} 2$ to $\mathrm{C} 4$. It was also observed that when the applied tensile strains did not cause sufficiently large cracks, the masonry compressive stresses would reverse any out-of-plane displacements that might have been experienced before the onset of instability.

A secondary factor that seems to play a role in determining the failure mode is the amount of reinforcement (reinforcement ratio) and the size of reinforcing bars. Based on the results of tests on specimen C5, it is speculated that the use of small bar sizes may cause severe de-bonding between a rebar and the grout core. This means that in the presence of large splitting cracks, local buckling of reinforcement takes priority over global out-of-plane instability as a failure mode. An estimate of the bar size and reinforcement ratio that will determine the difference between the onset of these two failure mechanisms requires further investigation.

This study was deemed an appropriate preliminary phase of the research program aimed at enhanced understanding of out-of-plane instability mechanism and the key parameters influencing its development. Further experimental studies on RMSW are required to improve the accuracy of predicting the limiting tensile strain levels and other factors that influence the occurrence of out-ofplane instability.

\section{AKNOWLEDGEMENTS}

This research project has been sponsored by the Natural Sciences and Engineering Research Council of Canada (NSERC) under the Collaborative Research and Development Program, Canadian Concrete Masonry Producers Association and the Masonry Institute of British Columbia. The first author acknowledges the support provided by the NSERC Industrial Postgraduate Scholarship program. The experimental testing would not be possible without the support provided by the UBC laboratory staff Scott Jackson and Blair Patterson, and Ken Zeleschuk, Assistant Instructor, BCIT Department of Civil Engineering. The authors acknowledge contribution of BCIT civil engineering students Dezmond 
Das, Paul Lam, and Porkeang Lim (the last student participated in the study through the NSERC Undergraduate Research Student Award in 2011).

\section{REFERENCES}

Anderson, D., and Brzev, S. 2009. Seismic Design Guide for Masonry Buildings. Canadian Concrete Masonry Producers Association, Toronto, Ontario, 317 pp (www.ccmpa.ca).

Azimikor, N. 2012. Out-Of-Plane Stability of Reinforced Masonry Shear Walls Under

Seismic Loading: Cyclic Uniaxial Tests. A Thesis Submitted in Partial Fulfilment of the

Requirements for the Degree of Master of Applied Science in the Faculty of Graduate Studies (Civil Engineering), The University of British Columbia, $180 \mathrm{pp}$.

Azimikor, N., Robazza, B.R., Elwood, K.J., Anderson, D.L., and Brzev, S. 2012. An

Experimental Study on the Out-of-Plane Stability of Reinforced Masonry Shear Walls under In-Plane

Reversed Cyclic Loads. Proceedings of the $15^{\text {th }}$ World Conference of Earthquake Engineering. Lisbon, Portugal.

Azimikor, N., Brzev, S., Elwood, K., and Anderson, D. 2011. Out-of-Plane Stability of Reinforced Masonry Shear Walls. Proceedings of the $11^{\text {th }}$ North American Masonry Conference, Minneapolis, MN, USA.

Chai, Y.H. and Elayer, D.T. 1999. Lateral Stability of Reinforced Concrete Columns under Axial Reversed Cyclic Tension and Compression. ACI Structural Journal, 96: 780-789.

CSA S304-14. 2014. Design of Masonry Structures. Canadian Standards Association, Mississauga, ON.

CSA S304.1-04. 2004. Design of Masonry Structures. Canadian Standards Association, Mississauga, ON.

CSA A165-04. 2004. CSA Standards on Concrete Masonry Units. Canadian Standards Association, Mississauga, ON.

CSA A179-04. 2004. Mortar and Grout for Unit Masonry. Canadian Standards Association, Mississauga, ON.

Elwood, K.J. 2013. Performance of Concrete Buildings in the 22 February 2011 Christchurch 
Earthquake and Implications for Canadian Codes, Canadian Journal of Civil Engineering, DOI:

10.1139/cjce-2011-0564.

Herrick, C.K. 2014. An Analysis of Local Out-of-Plane Buckling of Ductile Reinforced Structural Walls Due to In-Plane Loading, a Thesis submitted to the Graduate Faculty in partial fulfilment of the requirements for the degree of Master of Science, North Carolina State University, Raleigh, NC, 248 pp.

Paulay, T. and Priestley, M.J.N. 1993. Stability of Ductile Structural Walls. ACI Structural Journal, 90: 385-392.

Priestley, N.J. and He, L. 1992. Seismic Behaviour of Flanged Masonry Shear Walls. Final Report, U.S.-Japan Coordinated Program for Masonry Building Research, Department of Applied Mechanics and Engineering Sciences, University of California San Diego, CA, USA, 279 pp.

Robazza B.R. 2013. Out-of-Plane Stability of Reinforced Masonry Shear Walls under Seismic Loading: In-Plane Reversed Cyclic Testing, a Thesis submitted in partial fulfilment of the requirements for the degree of Master of Applied Science, Faculty of Graduate Studies, University of British Columbia, Vancouver, BC, 168 pp.

Robazza, B.R., Brzev, S., Elwood, K.J., Anderson, D.L., Yang, T., and McEwen, B. 2015. A Study on the Out-of-Plane Stability of Ductile Reinforced Masonry Shear Walls Subjected to In-Plane Reversed Cyclic Loading. Proceedings of the $12^{\text {th }}$ North American Masonry Conference, Denver, CO. Shedid, M.T., Drysdale, R.G., and El-Dakhakhni, W.W. 2008. Behaviour of Fully Grouted Reinforced Concrete Masonry Shear Walls in Flexure: Experimental Results. ASCE Journal of Structural Engineering, 134: 1754-1767.

Vallenas, J.M., Bertero, V.V., and Popov. E.P. 1979. Hysteretic Behaviour of Reinforced Concrete Structural Walls. Earthquake Engineering Research Centre, University of California, Berkeley, UBC/EERC-79/20, pp. 234.

Westenenk, B., de la Llera, J., Besa, J.J., Junemann, R., Moehle, J., Luders, C., Inaudi, J. A., Elwood, K.J., Hwang, S.J. 2012. Response of Reinforced Concrete Buildings in Concepcion during the Maule Earthquake. Eq. Spectra, Earthquake Engineering Research Institute, vol. 28, no. S1, S257-S280. 


\section{List of Figure Captions:}

Fig. 1 End zone of a shear wall subjected to axial tension and compression in end zones due to seismic loading.

Fig. 2 Test setup and instrumentation.

Fig. 3 Reversed cyclic loading protocol for specimens C2 to C5.

Fig. 4 Observed failure mechanisms: a) crushing; b) local reinforcement buckling, and c) global outof-plane instability.

Fig. 5 Generic axial force versus axial strain loading cycle for a masonry specimen under uniaxial cyclic tension and compression.

Fig. 6 Cracking patterns in specimen $\mathrm{C} 2$ : a) uniformly distributed horizontal cracks at bed joints (point $a^{\prime}$ on the load cycle), and b) rotated cracks (point $c$ on the load cycle).

Fig. 7 Axial load $(\mathrm{kN})$ vs. total axial deformation $(\mathrm{mm})$ for specimens $\mathrm{C} 2$ to $\mathrm{C} 5$.

Fig. 8 Axial load $(\mathrm{kN})$ vs. maximum lateral deformation $(\mathrm{mm})$ for specimens $\mathrm{C} 2$ to $\mathrm{C} 5$ (note that tension is shown with positive sign)

Fig. 9 Axial load versus tensile strain: key strain components. 
Table 1. Specimen Matrix

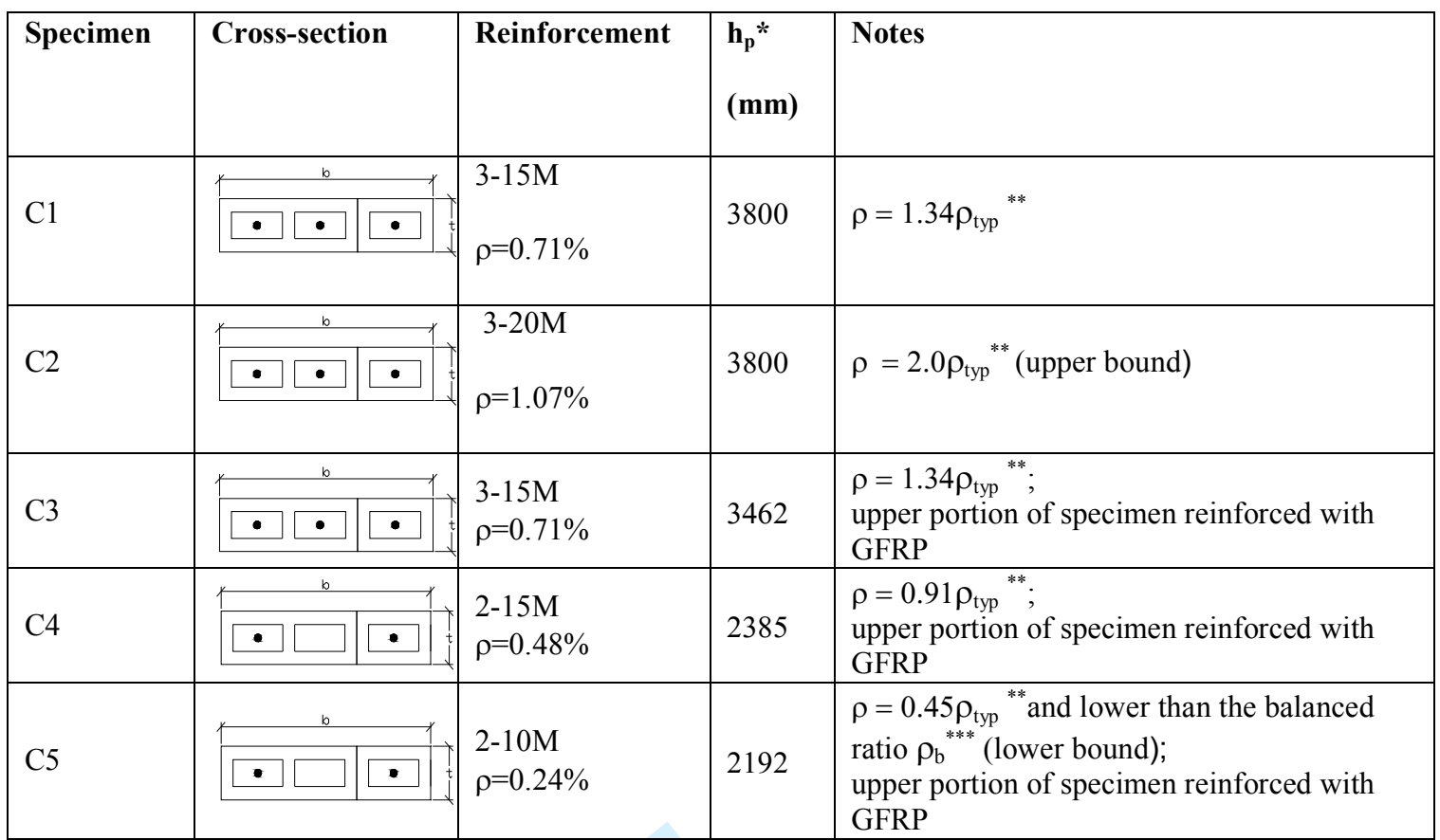

Notes:

* $\quad h_{p}$ is taken as the height over which tensile cracking was allowed; note that $h_{p}$ was reduced in specimens C3 to C5 using GFRP overlay.

** Standard practice is to provide $15 \mathrm{M}$ bars in cells located in the end zones of a RMSW built using standard $190 \mathrm{~mm} \times 190 \mathrm{~mm} \times 400 \mathrm{~mm}$ concrete masonry blocks; i.e. $\rho_{\mathrm{typ}}=0.53 \%$.

*** $\quad \rho_{\mathrm{b}}=0.36 \%$. 
Table 2. Critical experimental tensile strains leading to out-of-plane instability

\begin{tabular}{|c|c|c|c|c|c|}
\hline \multirow{2}{*}{ Specimen } & \multirow{2}{*}{$\frac{\delta_{\max }}{t}$} & \multicolumn{4}{|c|}{ Experimental Strains } \\
\hline & & $\varepsilon_{\mathrm{e}}$ & $\varepsilon_{\mathrm{r}}$ & $\varepsilon_{p}^{*}$ & $\varepsilon_{t}$ \\
\hline $\mathrm{C} 2$ & 0.435 & $0.30 \%$ & $0.10 \%$ & $0.39 \%$ & $0.79 \%$ \\
\hline $\mathrm{C} 3$ & 0.459 & $0.31 \%$ & $0.08 \%$ & $0.40 \%$ & $0.80 \%$ \\
\hline $\mathrm{C} 4$ & 0.404 & $0.39 \%$ & $0.18 \%$ & $1.13 \%$ & $1.69 \%$ \\
\hline $\mathrm{C} 5$ & 0.422 & $0.32 \%$ & $0.09 \%$ & $1.05 \%$ & $1.46 \%$ \\
\hline \multicolumn{6}{|l|}{ Notes: } \\
\hline 1 & \multirow{5}{*}{\multicolumn{5}{|c|}{$\begin{array}{l}\delta_{\max }=\text { maximum out-of-plane displacement for a test specimen } \\
\varepsilon_{\mathrm{e}}=\text { elastic strain } \\
\varepsilon_{\mathrm{r}}=\text { residual strain } \\
\varepsilon_{*_{\mathrm{p}}}=\text { plastic strain } \\
\varepsilon_{\mathrm{t}}=\text { total tensile strain (to be compared to theoretical maximum tensile strain } \varepsilon_{\mathrm{sm}}\end{array}$}} \\
\hline 2 & & & & & \\
\hline 3 & & & & & \\
\hline 4 & & & & & \\
\hline 5 & & & & & \\
\hline
\end{tabular}




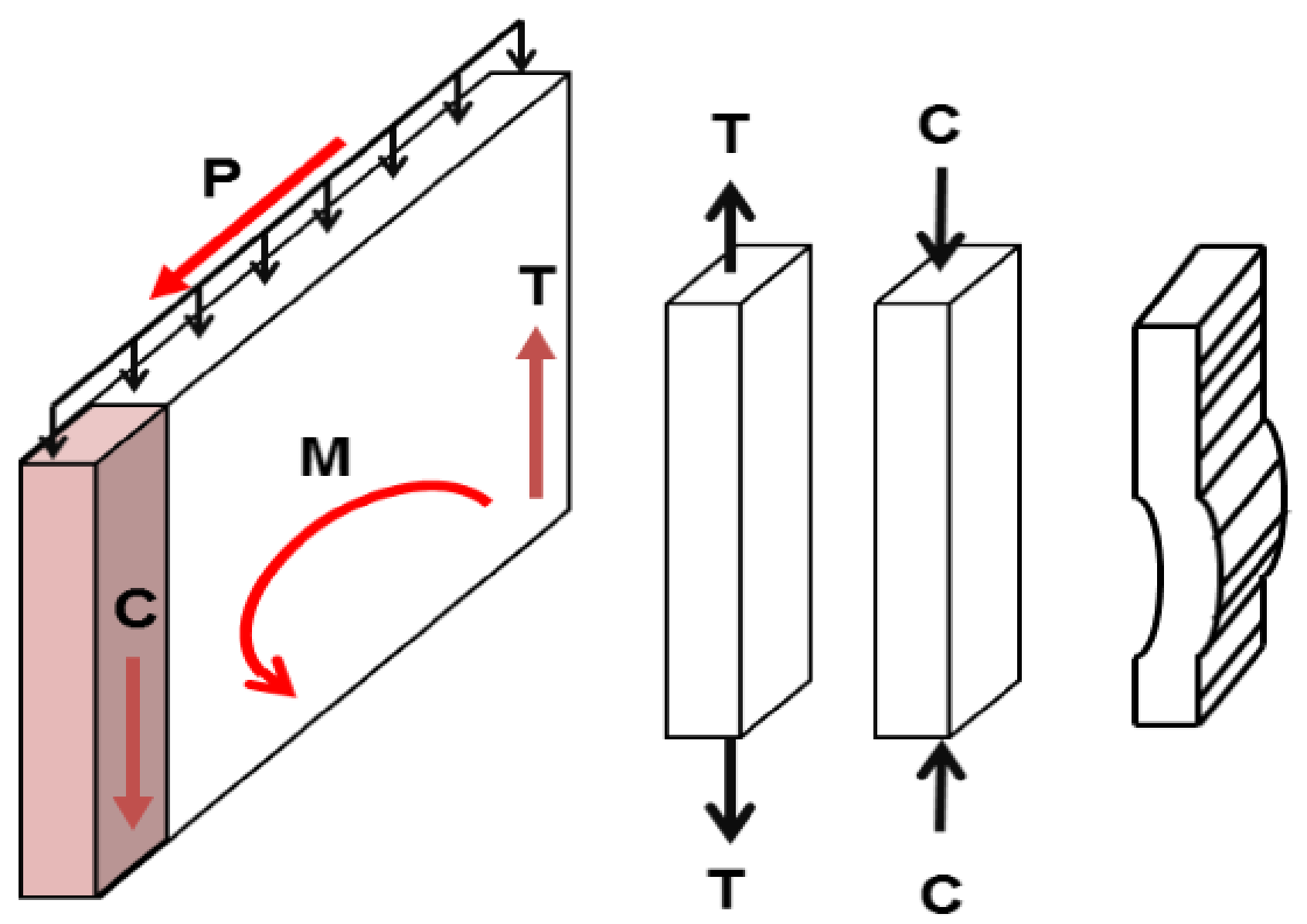


W310 COLUMN C/W BASE PLATE TO HOLD LATERAL SUPPORT SYSTEM (i.e. PANTOGRAPHS)

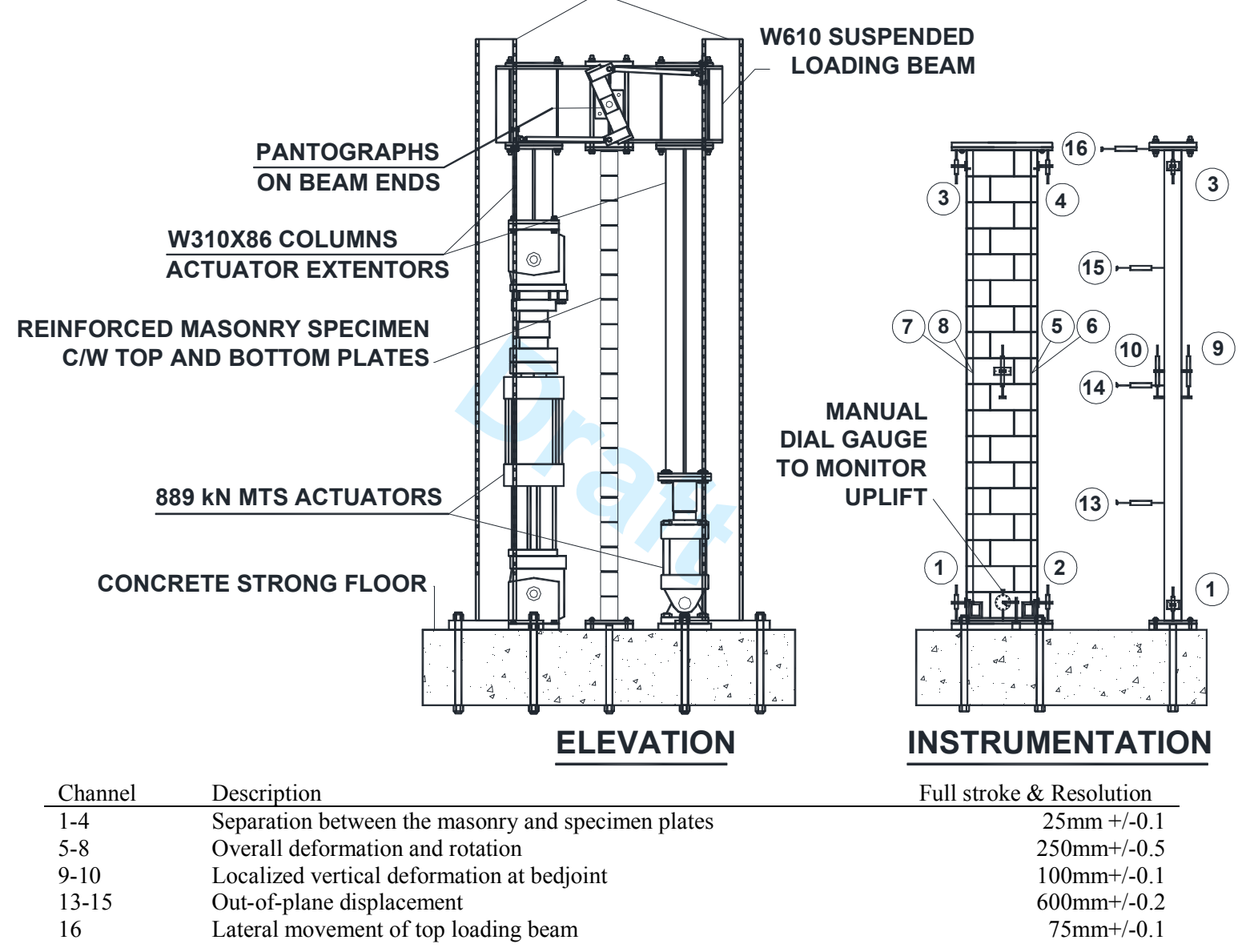

Instrumentation 11 and 12 were removed from the set up 


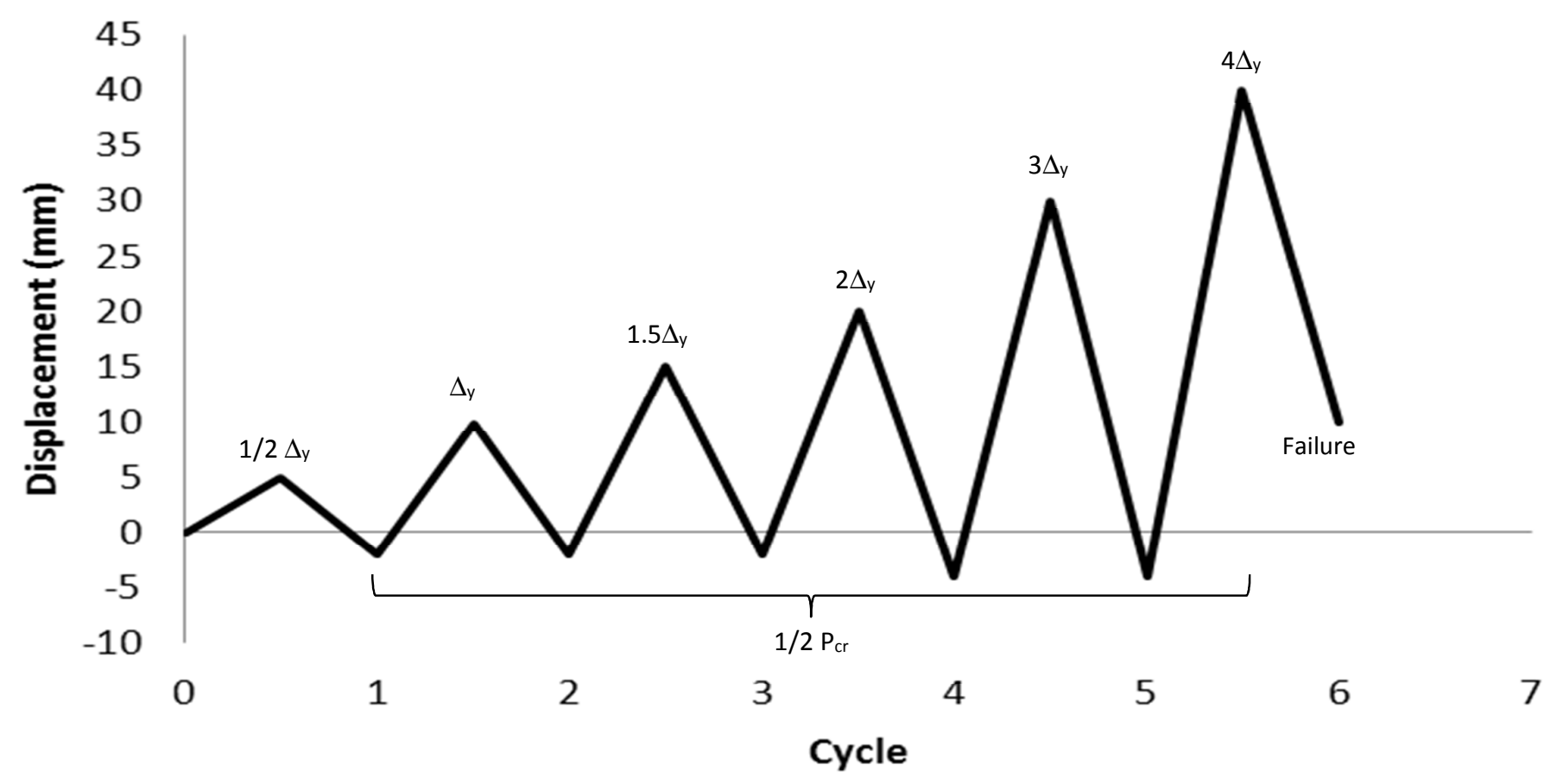




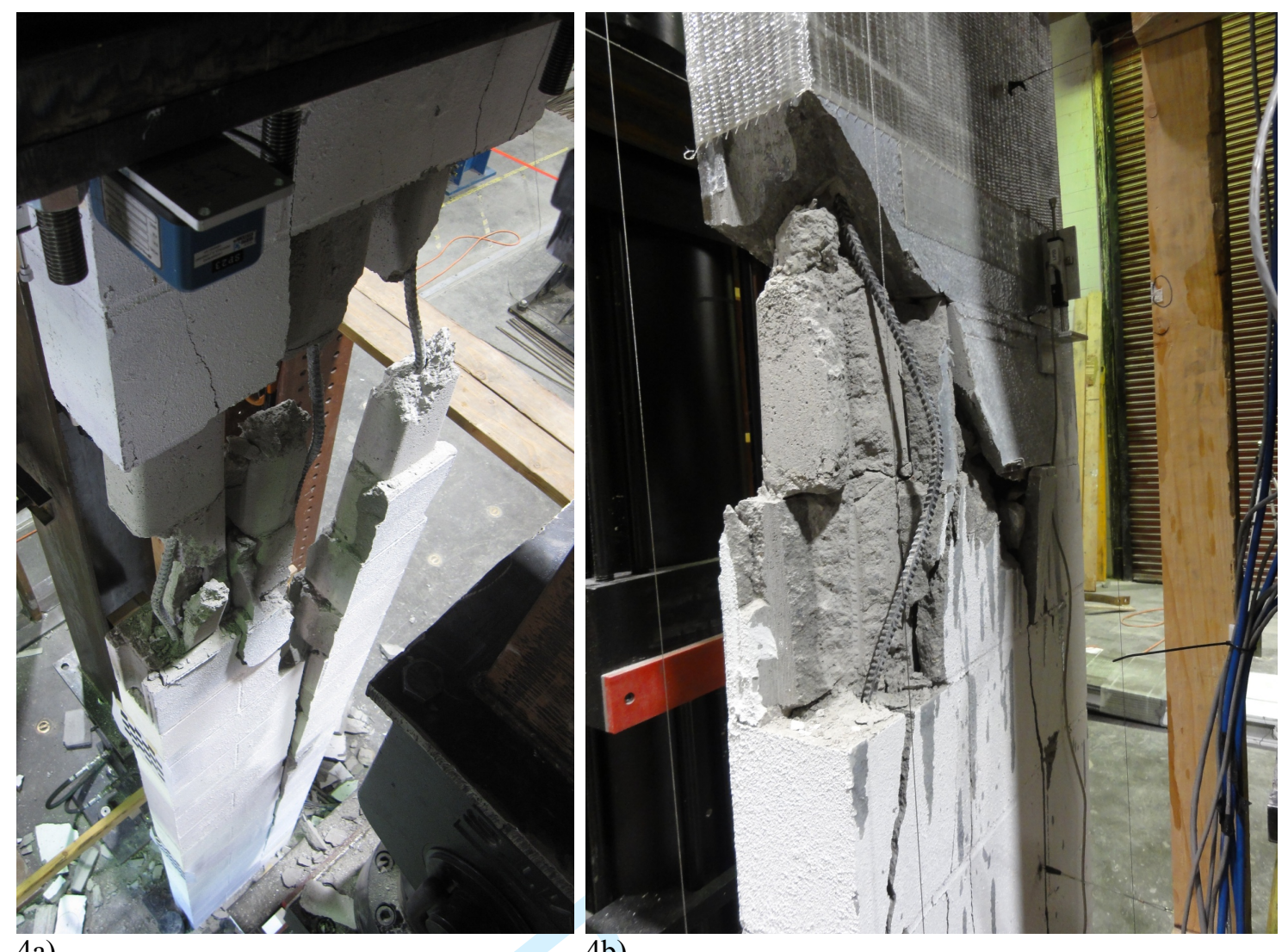

4a)

4b)

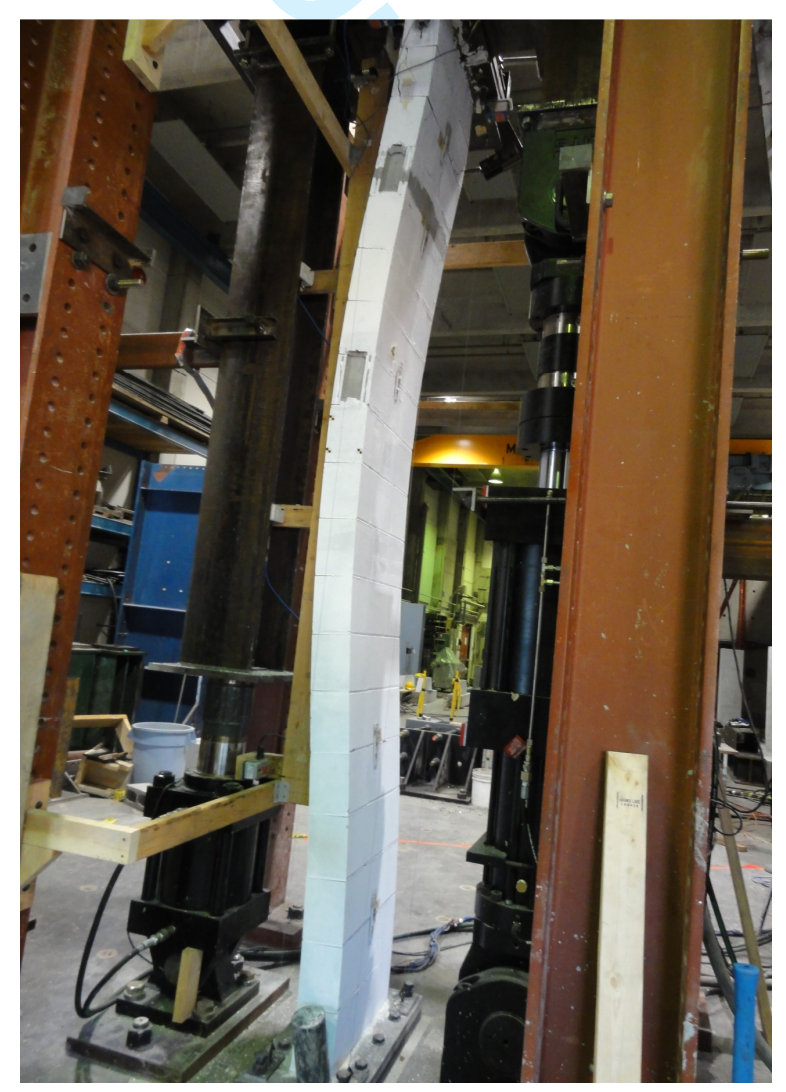

$4 c)$ 


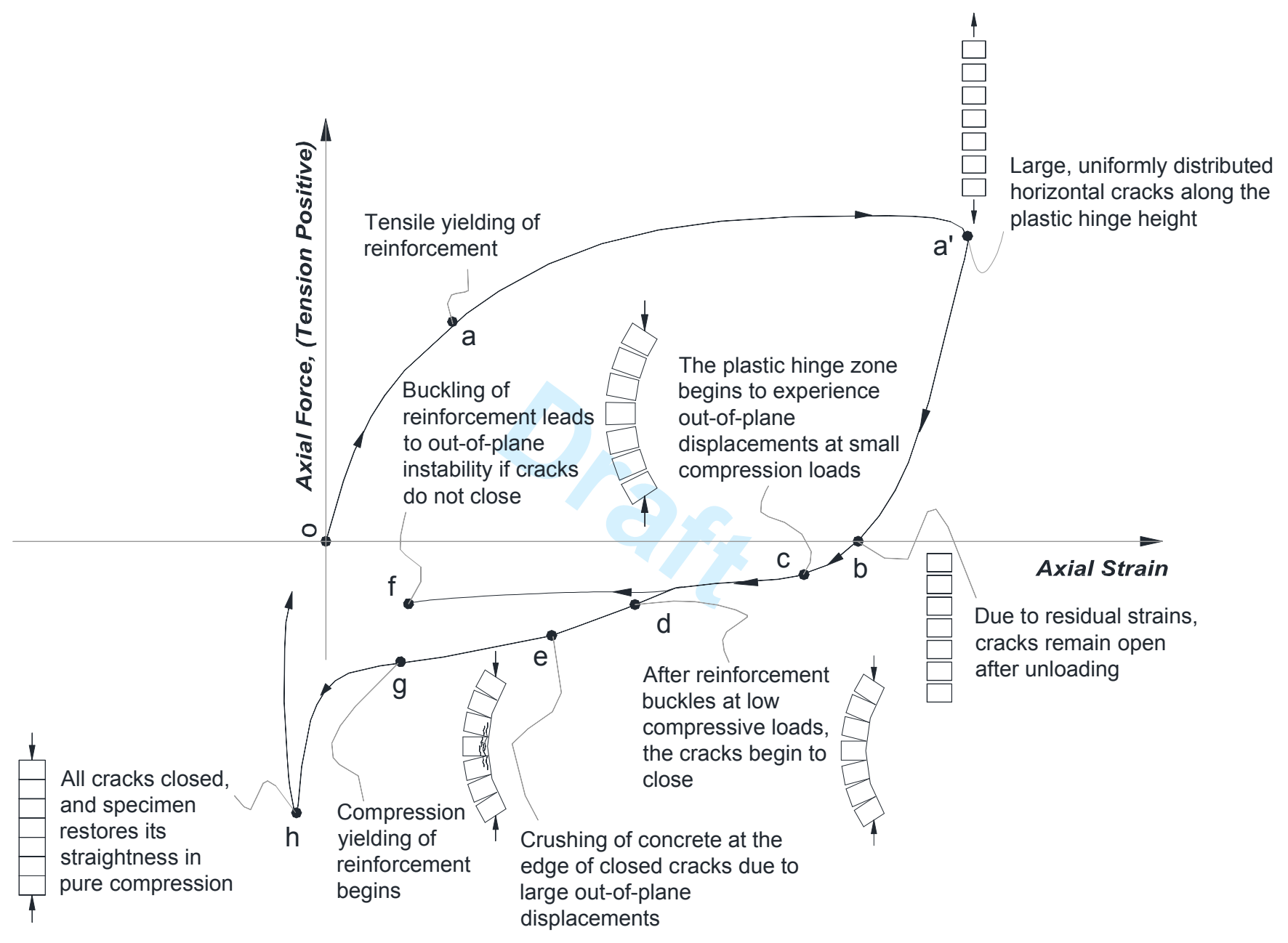

https://mc06.manuscriptcentral.com/cjce-pubs 


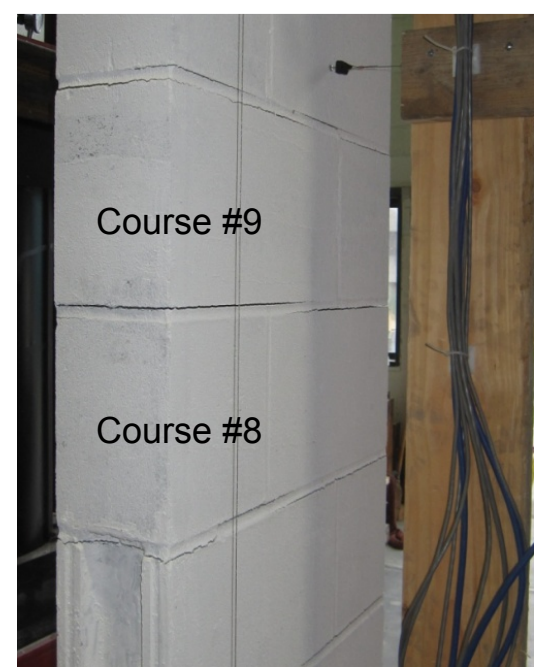

a)

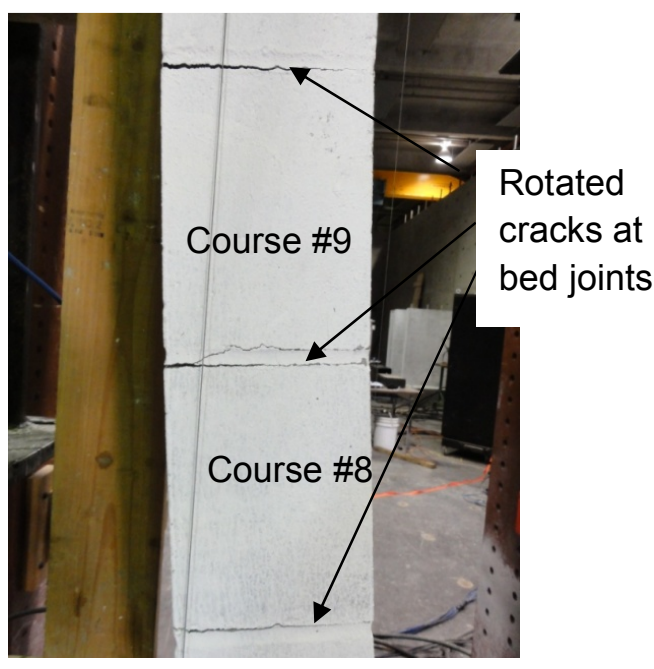

b) 


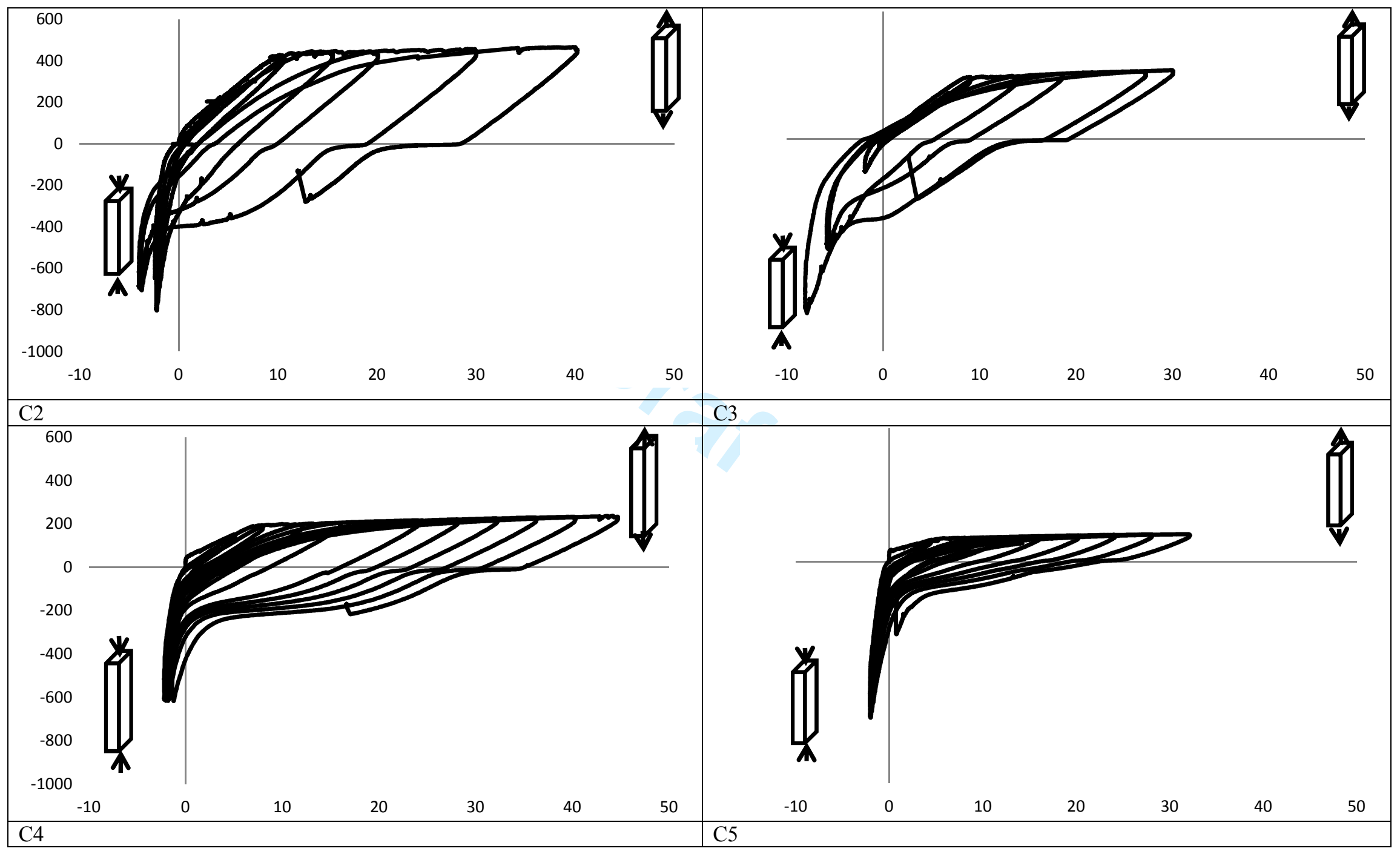




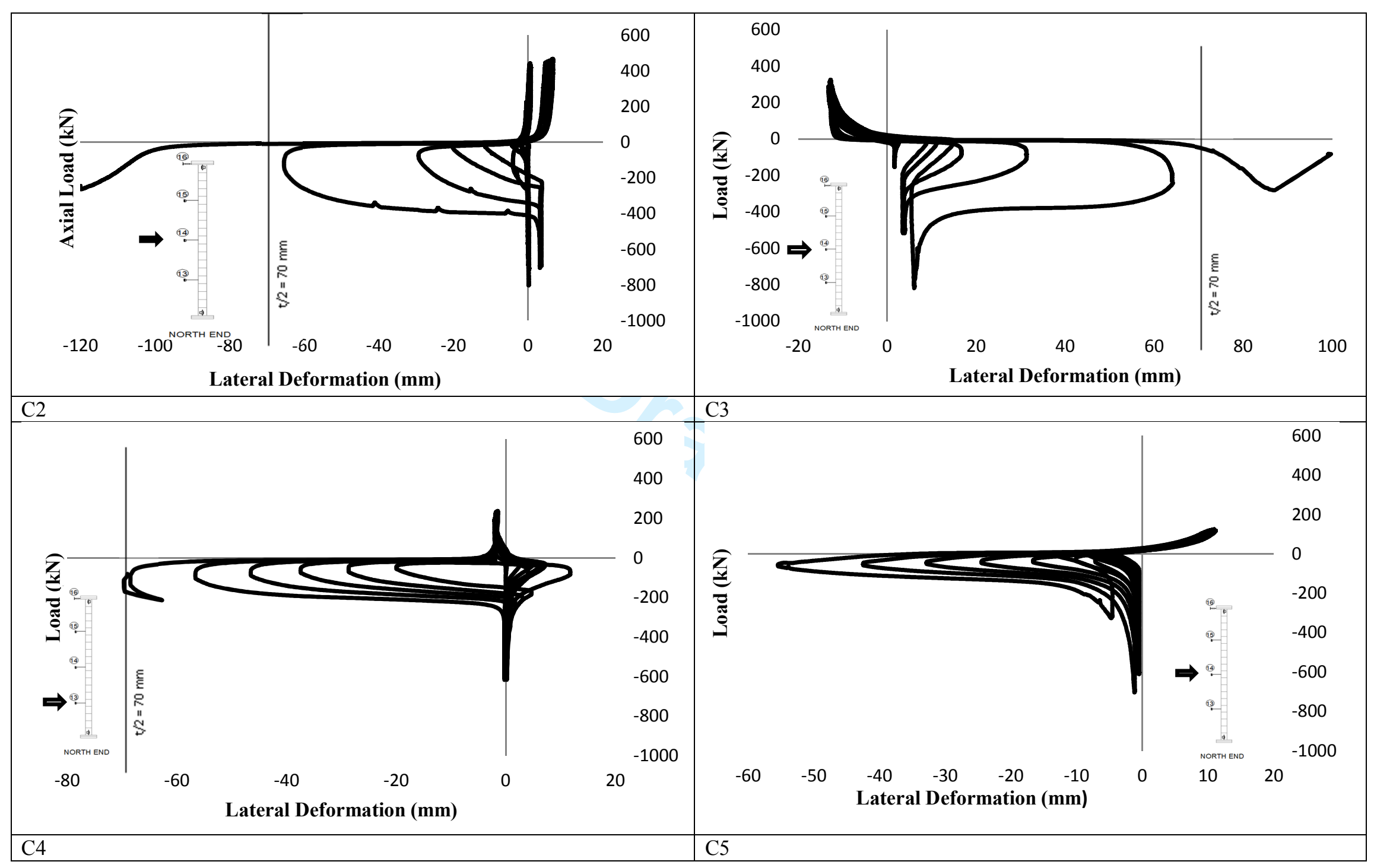




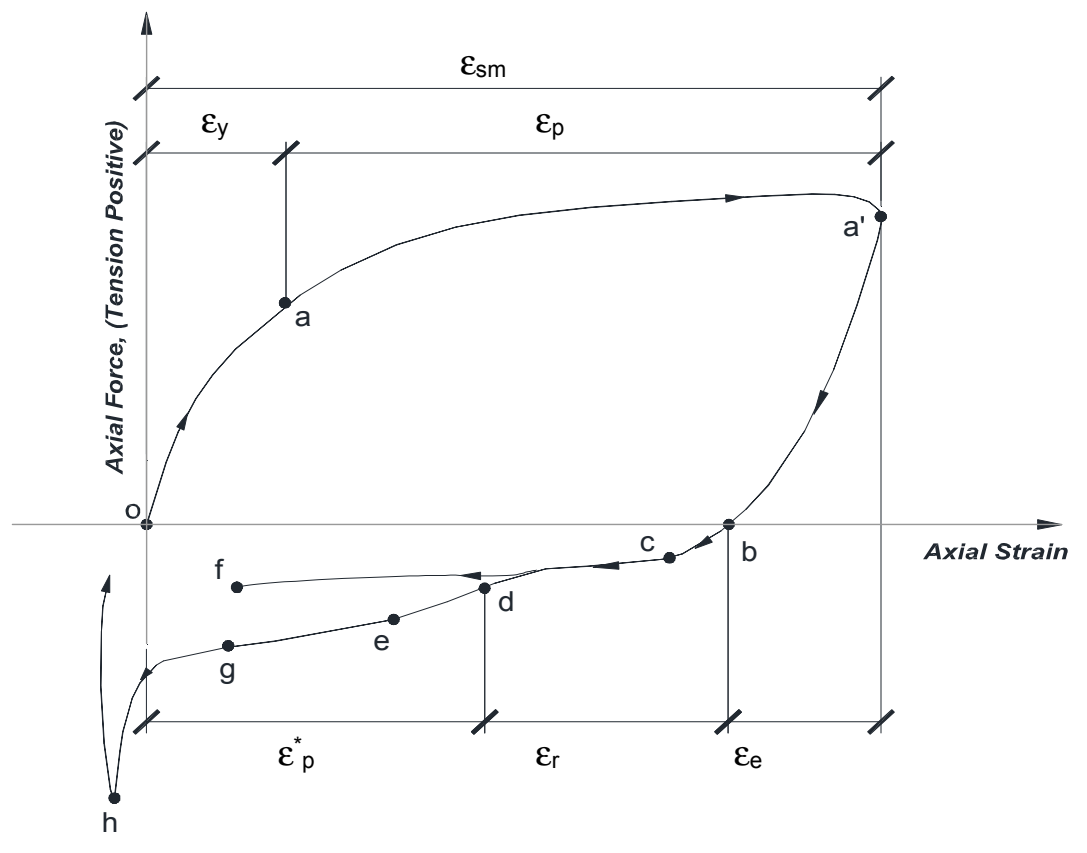

